\title{
Theoretical Study of Terminal Vanadium(V) Chalcogenido Complexes Bearing Chlorido and Methoxido Ligands
}

\author{
Samuel Tetteh and Ruphino Zugle \\ Chemistry Department, School of Physical Sciences, College of Agriculture and Natural Sciences, \\ University of Cape Coast, Cape Coast, Ghana \\ Correspondence should be addressed to Samuel Tetteh; stoshgh2001@yahoo.com
}

Received 4 September 2017; Accepted 24 October 2017; Published 15 November 2017

Academic Editor: Teodorico C. Ramalho

Copyright (C) 2017 Samuel Tetteh and Ruphino Zugle. This is an open access article distributed under the Creative Commons Attribution License, which permits unrestricted use, distribution, and reproduction in any medium, provided the original work is properly cited.

\begin{abstract}
Solvent (methanol) coordinated vanadium(V) chalcogenido complexes bearing chlorido and methoxido ligands have been studied computationally by means of density functional (DFT) methods. The gas phase complexes were fully optimized using B3LYP/GEN functionals with $6-31+\mathrm{G}^{* *}$ and LANL2DZ basis sets. The optimized complexes show distorted octahedral geometries around the central vanadium atom. The ligand $\mathrm{p} \pi$-vanadium $\mathrm{d} \pi$ interactions were analyzed by natural bond order $(\mathrm{NBO})$ and natural population analyses (NPA). These results show strong stabilization of the $\mathrm{V}=\mathrm{O}$ bond as was further confirmed by the analyses of the frontier molecular orbitals (FMOs). Second-order perturbation analyses also revealed substantial delocalization of lone pair electrons from the oxido ligand into vacant non-Lewis (Rydberg) orbitals as compared to the sulfido and seleno analogues. These results show significant ligand-to-metal charge transfer (LMCT) interactions. Full interaction map (FIM) of the reference complex confirms hydrogen bond interactions involving the methanol $(\mathrm{O}-\mathrm{H})$ and the chlorido ligand.
\end{abstract}

\section{Introduction}

Chalcogens (Ch) (group of 16 elements) form one of the interesting groups of elements on the periodic table. They represent the first group of nonmetals for which all the nonradioactive members (except Po) are known to form multiple bonds with the transition metals [1]. The study of complexes with terminal metal-oxo, sulfido, seleno, and related ligands is an interesting area of inorganic chemistry. This is partly because they are used as reagents and precatalysts $[2,3]$ for organic synthesis and also as models for the active sites in heterogeneous processes. A search in the Cambridge Structural Database (version 5.38, November 2016, plus one update) reveals that the occurrence of terminal chalcogenido complexes diminishes rapidly in the sequence $\mathrm{O} \gg \mathrm{S}>\mathrm{Se}>$ Te making the oxo complexes the most prevalent.

Vanadium chalcogenido complexes are known for their biological and catalytic functions [4-7]. The metal forms a large number of complexes with oxidation states ranging from $-\mathrm{III}$ to $+\mathrm{V}$ with majority of these complexes being oxovanadium complexes [8]. This preference of vanadium for oxygen has been illustrated by the reactivity of $\mathrm{VS}_{4}{ }^{3-}$, which dissolves in aqueous bases to give deep violet solutions but spontaneously decomposes to brown oxygen-containing materials [8]. Oxovanadium $(\mathrm{V})$ complexes have been extensively employed as (pre)catalysts in oxidation reactions [9, 10], sulfoxidation processes [11], olefin epoxidation [4], and polymerization reactions involving ethene and styrene [12, 13].

Interest in softer chalcogen ( $\mathrm{S}$ and $\mathrm{Se}$ ) containing complexes is rapidly increasing because of their potential application in bioinorganic and coordination chemistry [14]. Covalent bonds involving these atoms have been shown to exhibit a localized region of positive potential which allows them to interact with electron donors to form typical noncovalent interactions similar to halogen bonds [15]. Another important property of the heavier chalcogens is the ability to form $\pi$-bonds. Using the CSD searches, Reid et al. have shown that sulfur- $\pi$ interactions are more frequent in biological systems than previously thought [16]. These $\pi$-interactions are important in stabilizing high valent transition metal ions (such as $\mathrm{V}(\mathrm{V})$ ) by $\mathrm{Ch} \mathrm{p} \pi-\mathrm{M} \mathrm{d} \pi$ interactions. In this 
TABLE 1: Selected bond lengths $(\AA)$ and angles $\left(^{\circ}\right)$ for the respective complexes.

\begin{tabular}{|c|c|c|c|c|}
\hline \multirow{2}{*}{ Parameter } & \multirow{2}{*}{ Experimental $^{\mathrm{ref}}$} & \multicolumn{3}{|c|}{ Calculated } \\
\hline & & $\mathrm{A}$ & $\mathrm{B}$ & $\mathrm{C}$ \\
\hline $\mathrm{V}-\mathrm{Ch}$ & $1.5778(16)$ & 1.561 & 2.002 & 2.147 \\
\hline $\mathrm{V}-\mathrm{O}(6)$ & $1.7446(15)$ & 1.737 & 1.727 & 1.724 \\
\hline $\mathrm{V}-\mathrm{O}(2)$ & $2.1132(16)$ & 2.250 & 2.257 & 2.250 \\
\hline $\mathrm{V}-\mathrm{O}(7)$ & $2.2268(16)$ & 2.403 & 2.444 & 2.426 \\
\hline $\mathrm{V}-\mathrm{Cl}(4)$ & $2.3108(7)$ & 2.314 & 2.318 & 2.331 \\
\hline $\mathrm{V}-\mathrm{Cl}(3)$ & $2.3442(8)$ & 2.333 & 2.328 & 2.317 \\
\hline $\mathrm{Ch}-\mathrm{V}-\mathrm{O}(6)$ & $99.65(8)$ & 100.74 & 100.74 & 101.17 \\
\hline $\mathrm{Ch}-\mathrm{V}-\mathrm{O}(2)$ & $92.33(8)$ & 94.83 & 96.11 & 96.06 \\
\hline Ch-V-O(7) & $171.62(8)$ & 173.99 & 172.61 & 171.94 \\
\hline $\mathrm{O}(6)-\mathrm{V}-\mathrm{O}(2)$ & $167.77(7)$ & 163.93 & 161.92 & 162.52 \\
\hline $\mathrm{O}(6)-\mathrm{V}-\mathrm{Cl}(4)$ & $96.68(6)$ & 97.65 & 97.32 & 96.27 \\
\hline $\mathrm{O}(2)-\mathrm{V}-\mathrm{Cl}(4)$ & $84.26(5)$ & 83.64 & 83.68 & 83.61 \\
\hline $\mathrm{O}(6)-\mathrm{V}-\mathrm{Cl}(3)$ & $94.64(5)$ & 96.10 & 95.46 & 96.22 \\
\hline $\mathrm{O}(2)-\mathrm{V}-\mathrm{Cl}(3)$ & $81.38(5)$ & 77.27 & 76.94 & 77.22 \\
\hline
\end{tabular}

ref: [17], A: $\mathrm{VOCl}_{2}(\mathrm{OMe})(\mathrm{HOMe})_{2}, \mathrm{~B}: \mathrm{VSCl}_{2}(\mathrm{OMe})(\mathrm{HOMe})_{2}$, and C: $\mathrm{VSeCl}_{2}(\mathrm{OMe})(\mathrm{HOMe})_{2}$.

manuscript, we report results of CSD searches for terminal vanadium(V) chalcogenido complexes bearing chlorido and methoxido ligands with coordinated methanol molecules. We also study the effect of varying the chalcogenido atom on the occupancy and energy of the vanadium-d orbitals by keeping the ancillary ligands constant. Furthermore, we have analyzed the full interaction map of the oxidovanadium complex using the Mercury program to identify possible contacts for intermolecular interactions and compared with data reported in the literature [17].

\section{Methodology}

2.1. CSD Analysis. Version 5.38 of the CSD (November 2016) plus one update was used for the analysis of the full interaction maps. The CSD program ConQuest version 1.19 was used to perform substructure searches of oxido, sulfido, and seleno vanadium(V) complexes bearing chlorido, methanol, and methoxido ligands. The following search filters were employed: 3D coordinates determined; crystallographic $R$ factor $\leq 0.05$; no disorder in the crystal structure; no errors in the structure; no polymeric bonding; no ions; no powder structures and only organometallic structures (according to the standard CSD definitions) [18]. The search revealed two crystal structures in the CCDC database with refcodes EREGAJ [19] and FUYXAZ [17]. The former is an oxovanadium(IV) complex with three methanol ligands and two cis chlorido ligands with $z^{\prime}=2$. FUYXAZ however is an oxovanadium $(\mathrm{V})$ with the required set of ligands with $z^{\prime}=1$. Therefore FUYXAZ was chosen for the theoretical studies. The search however revealed that there was no crystal structure for the sulfido and seleno analogues in the CCDC database as at the time of preparing this manuscript. The CSD program Mercury version 3.9 was used for the structural visualization [20]. To perform the full interaction map, probes such as alcohol oxygen, carbonyl oxygen, methyl carbon, and $\mathrm{C}-\mathrm{Cl}$ chloride were used as proxies to provide interaction maps which indicate positions of hydrogen bond acceptors (shown in red), donors (blue), and any possibility of halogen bonding [20].

2.2. Computational Studies. The input files of the respective complexes were prepared using the GaussView 5.0.8 molecular structure viewer [21]. All calculations were performed using the Gausssian09 program [22]. Full unconstrained geometry optimization of the complexes was carried out at the density functional theory (DFT) using Becke's threeparameter hybrid method and the Lee-Yang-Parr correlation functional (B3LYP) [23]. DFT computations have become effective tools for analyzing structure, bonding, reactivity, and properties of transition metal complexes. Effective core potentials (ECP) were used to represent the valence electrons of vanadium and the basis set of double- $\zeta$ quality associated with the pseudopotentials known as LANL2DZ [24]. The 6$31+\mathrm{G}^{* *}[25]$ basis set was used for all other atoms. Vibrational frequency analyses confirmed that the optimized structures were at stationary points corresponding to local minima without imaginary frequencies. Natural bond orbital (NBO) analysis and natural population analysis (NPA) were used to estimate the net atomic charges and electronic configurations of the respective atoms. Frontier molecular orbitals (FMO) and molecular electrostatic potential (MEP) were performed at the same level of theory.

\section{Results and Discussion}

3.1. Geometry Optimization. The optimized geometries and selected atomic numbering scheme of the complexes in the gas phase are shown in Figure 1.

Selected bond lengths and angles of the optimized and reference structures are listed in Table 1. Generally, each vanadium atom adopts a distorted octahedral geometry with one methanol oxygen trans to the $\mathrm{Ch}$ ligand. The neutrality of the methanol ligand reduces the trans effect on the $\mathrm{Ch}$ 

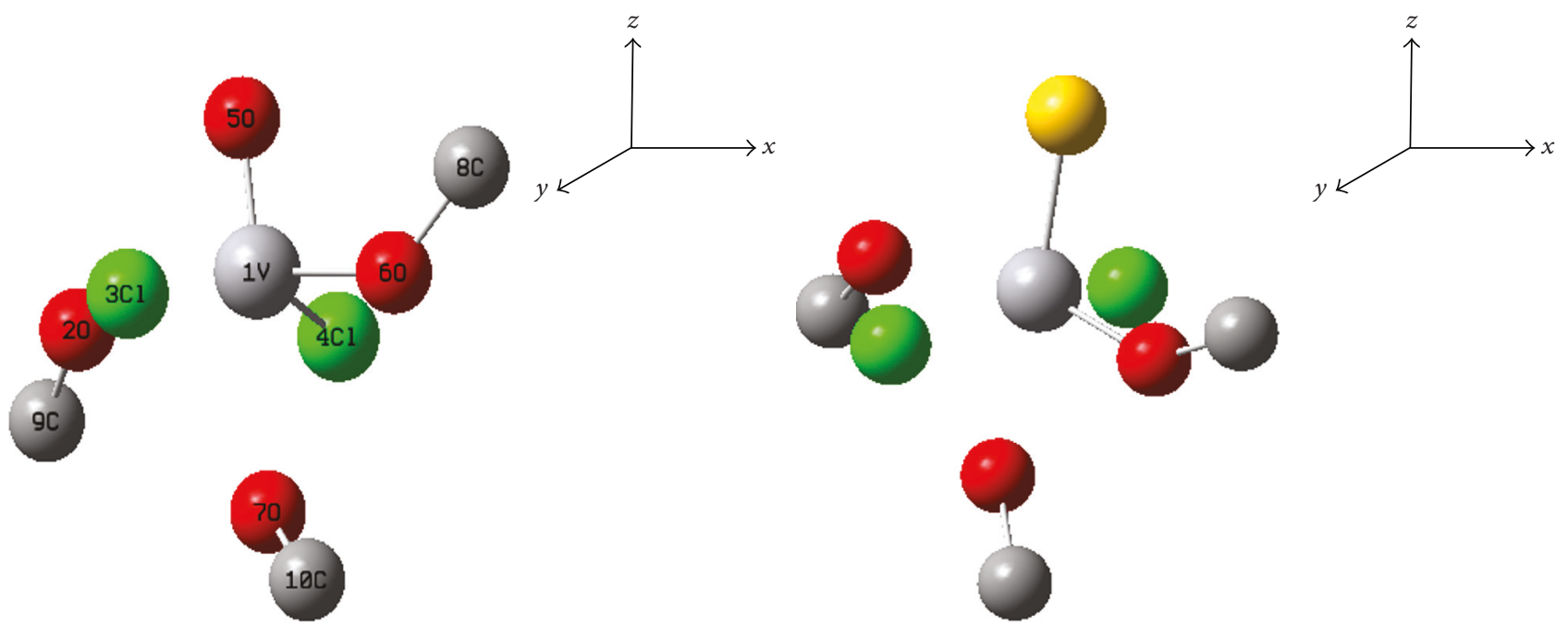

(A)

(B)

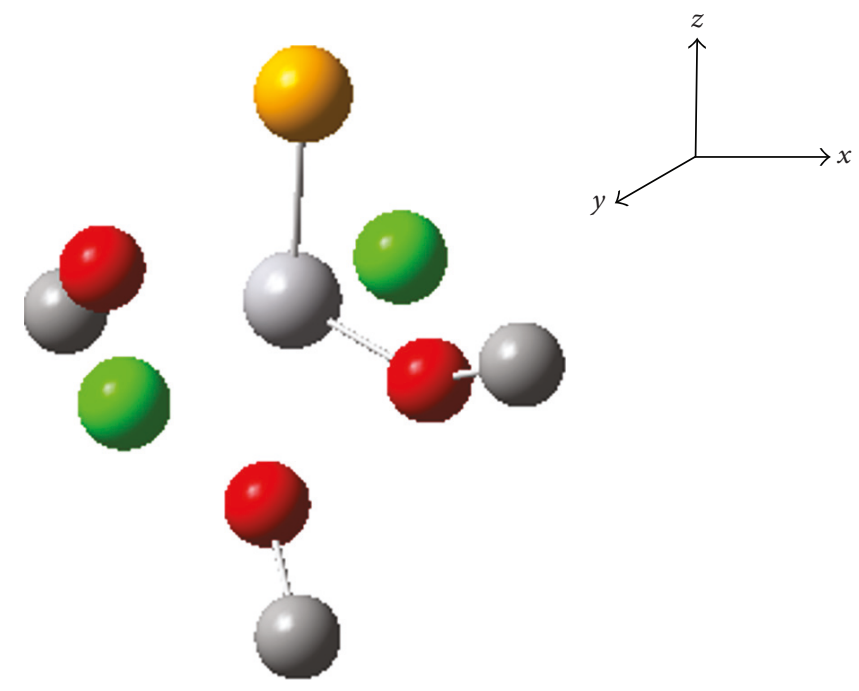

(C)

Figure 1: Optimized geometries of the respective complexes. A: $\mathrm{VOCl}_{2}(\mathrm{OMe})(\mathrm{HOMe})_{2}, \mathrm{~B}$ : $\mathrm{VSCl}{ }_{2}(\mathrm{OMe})\left(\mathrm{HOMe}_{2}\right.$, and $\mathrm{C}$ : $\mathrm{VSeCl}_{2}(\mathrm{OMe})(\mathrm{HOMe})_{2}$. Hydrogen atoms have been removed for clarity.

ligand and also minimizes competition for the $\mathrm{d} \pi$ orbitals [26]. The two equatorial chlorido ligands are positioned trans to each other with the methoxido oxygen and the remaining methanol also adopting trans positions.

The selected bond lengths and angles of the optimized oxido complex compare favorably with those of the reference compound. The slight differences are as a result of the fact that the theoretical calculations were carried out on a single molecule in the gas phase, whereas in the crystal there are lattice interactions which could affect the bond parameters. From Table 1, the $\mathrm{V}=\mathrm{Ch}$ bond lengths increase from $\mathrm{O}$ to $\mathrm{Se}$ as expected. However, the reverse is found for the V$\mathrm{O}(6)$ bond. Another observed anomaly is the changes in the $\mathrm{V}-\mathrm{Cl}$ bond lengths despite the fact that the chlorido ligands are equatorial and trans to each other. Whereas the $\mathrm{V}-\mathrm{Cl}(4)$ bond length increased in moving from $\mathrm{O}$ to
Se, the $\mathrm{V}-\mathrm{Cl}(3)$ bond length rather decreased. The $\mathrm{Ch}-\mathrm{V}$ $\mathrm{O}(6)$ bond angle remains unchanged in moving from $\mathrm{O}$ to $\mathrm{S}$ but increases by $0.43^{\circ}$ in the case of Se. This can be attributed to the relatively large electron cloud around the Se ligand which could repel the electrons in the $\mathrm{V}-\mathrm{O}(6) \sigma$-bond thereby increasing the $\mathrm{Se}-\mathrm{V}-\mathrm{O}(6)$ angle. A series of density functional theory (DFT) calculations were carried out to fully understand and complement the data in Table 1.

3.2. Natural Bond Orbital (NBO) Analysis and Charge Distribution. NBO and second-order perturbation theory analysis of Fock Matrix provide details about the electron distribution in the various atomic and molecular orbitals and the strength of the interactions between metal ions and donor atoms [27]. From Table 2, the electronic configuration of vanadium in the oxido complex is given as [core] $4 \mathrm{~s}^{0.27} 3 \mathrm{~d}^{3.74} 4 \mathrm{p}^{0.49}, 17.9762$ 
TABLE 2: Electronic configuration of selected atoms.

\begin{tabular}{|c|c|c|c|}
\hline \multirow{2}{*}{ Atom } & \multicolumn{3}{|c|}{ Electronic configuration } \\
\hline & A & B & $\mathrm{C}$ \\
\hline $\mathrm{V}(1)$ & {$\left[\right.$ core] $4 \mathrm{~s}^{0.27} 3 \mathrm{~d}^{3.74} 4 \mathrm{p}^{0.49}$} & [core] $4 \mathrm{~s}^{0.32} 3 \mathrm{~d}^{4.23} 4 \mathrm{p}^{0.64}$ & [core] $4 \mathrm{~s}^{0.35} 3 \mathrm{~d}^{4.25} 4 \mathrm{p}^{0.7}$ \\
\hline $\mathrm{O}(2)$ & {$[$ core $] 2 \mathrm{~s}^{1.64} 2 \mathrm{p}^{5.05}$} & {$[$ core $] 2 \mathrm{~s}^{1.64} 2 \mathrm{p}^{5.05}$} & {$[$ core $] 2 \mathrm{~s}^{1.63} 2 \mathrm{p}^{5.04}$} \\
\hline $\mathrm{Cl}(3)$ & {$[$ core $] 3 \mathrm{~s}^{1.86} 3 \mathrm{p}^{5.40}$} & {$\left[\right.$ core] $3 \mathrm{~s}^{1.85} 3 \mathrm{p}^{5.37}$} & {$[$ core $] 3 \mathrm{~s}^{1.85} 3 \mathrm{p}^{5.36}$} \\
\hline $\mathrm{Cl}(4)$ & {$[$ core $] 3 \mathrm{~s}^{1.86} 3 \mathrm{p}^{5.38}$} & [core] $3 \mathrm{~s}^{1.85} 3 \mathrm{p}^{5.37}$ & {$\left[\right.$ core] $3 \mathrm{~s}^{1.85} 3 \mathrm{p}^{5.38}$} \\
\hline $\mathrm{O}(5)$ & [core] $2 \mathrm{~s}^{1.78} 2 \mathrm{p}^{4.39}$ & - & - \\
\hline$S(21)$ & - & {$\left[\right.$ core] $3 \mathrm{~s}^{1.74} 3 \mathrm{p}^{3.86}$} & - \\
\hline $\operatorname{Se}(21)$ & - & - & {$[$ core $] 4 \mathrm{~s}^{1.75} 4 \mathrm{p}^{3.79}$} \\
\hline $\mathrm{O}(6)$ & {$[$ core $] 2 \mathrm{~s}^{1.63} 2 \mathrm{p}^{4.77}$} & {$\left[\right.$ core] $2 \mathrm{~s}^{1.61} 2 \mathrm{p}^{4.76}$} & {$[$ core $] 2 \mathrm{~s}^{1.60} 2 \mathrm{p}^{4.76}$} \\
\hline $\mathrm{O}(7)$ & [core $] 2 \mathrm{~s}^{1.66} 2 \mathrm{p}^{5.06}$ & [core] $2 \mathrm{~s}^{1.66} 2 \mathrm{p}^{5.05}$ & {$[$ core $] 2 \mathrm{~s}^{1.66} 2 \mathrm{p}^{5.04}$} \\
\hline
\end{tabular}

A: $\mathrm{VOCl}_{2}(\mathrm{OMe})(\mathrm{HOMe})_{2}, \mathrm{~B}: \mathrm{VSCl}_{2}(\mathrm{OMe})(\mathrm{HOMe})_{2}$, and C: $\mathrm{VSeCl}_{2}(\mathrm{OMe})(\mathrm{HOMe})_{2}$.

TABLE 3: NPA charge distribution of respective atoms in the complexes.

\begin{tabular}{lccc}
\hline Atom & \multicolumn{3}{c}{ Charge } \\
& A & B & C \\
\hline $\mathrm{V}(1)$ & 0.447 & -0.222 & -0.331 \\
$\mathrm{O}(2)$ & -0.715 & -0.707 & -0.681 \\
$\mathrm{Cl}(3)$ & -0.270 & -0.235 & -0.212 \\
$\mathrm{Cl}(4)$ & -0.251 & -0.228 & -0.233 \\
$\mathrm{O}(5)$ & -0.187 & - & - \\
$\mathrm{S}(21)$ & - & 0.391 & - \\
$\mathrm{Se}(21)$ & - & - & 0.445 \\
$\mathrm{O}(6)$ & -0.420 & -0.394 & -0.377 \\
$\mathrm{O}(7)$ & -0.749 & -0.744 & -0.716 \\
\hline $\mathrm{A}: \quad \mathrm{VOCl}_{2}(\mathrm{OMe})(\mathrm{HOMe})_{2}$, & $\mathrm{B}:$ & $\mathrm{VSCl}_{2}(\mathrm{OMe})(\mathrm{HOMe})_{2}$, & and $\mathrm{C}$ \\
$\mathrm{VSeCl}$ & & &
\end{tabular}

core electrons, 4.5023 valence electrons, and 0.07505 Rydberg electrons. This gives a total of 22.5536 electrons, which is consistent with the natural population analysis (NPA) charge of +0.447 (Table 3 ).

Similar charges of -0.222 and -0.331 were calculated for the sulfido and selenido congeners. These reduced ionic charges can be attributed to the significant charge delocalization from the respective $\mathrm{Ch}$ ligand. As shown in Table 2, the p-orbital configurations for the Ch ligands are as follows: 4.39 , 3.86, and 3.79 for O, S, and Se, respectively. This shows that the Se ligand has the highest delocalization power therefore contributing significantly to the reduction of the ionic charge on $\mathrm{V}$ to -0.331 . From Figure 2, the electrophilic and nucleophilic regions in the complex are illustrated using the molecular electrostatic potential map (MEP). These regions describe the chemical reactivity of the complex. A red colour represents electron rich sites while a blue colour represents electrophilic sites. As shown, the electrostatic potential on the oxido ligand is more electron rich than that on the sulfido and seleno ligands probably due to the greater electron delocalization from the latter.

The presence of empty vanadium $t_{2 g}$ orbitals makes it possible for the formation of ligand-to-metal $\pi$ bonds. The metal $\mathrm{d}_{y z}$ and $\mathrm{d}_{x z}$ orbitals have the symmetry to overlap with the $\mathrm{p}$ and $\mathrm{d}$ orbitals of the respective $\mathrm{Ch}$ ligand to form multiple bonds. From Table 4 , the $\mathrm{d}_{x z}$ and $\mathrm{d}_{y z}$ orbitals of suitable symmetry for $\mathrm{Ch} \mathrm{p} \pi-\mathrm{V} \mathrm{d} \pi$ bonding are the highest occupied orbitals and have reduced energies. For the oxido complex, the $\mathrm{d}_{y z}$ orbital is the highest occupied (0.8034) with energy of $-0.230 \mathrm{eV}$. Similarly, the $\mathrm{V} \mathrm{d}_{y z}$ orbital of the sulfido complex has the highest occupancy of 0.9646 with a corresponding energy of $-0.238 \mathrm{eV}$. However, the $\mathrm{d}_{x z}$ orbital (a $\mathrm{V} \mathrm{d} \pi$-bonding orbital) of the seleno complex is the highest occupied with $-0.205 \mathrm{eV}$. The strong delocalization of $\mathrm{Ch}$ $\mathrm{p} \pi$ electrons into corresponding $\mathrm{V} \mathrm{d} \pi$ orbitals contributes significantly to the reduction of the ionic charge from $+\mathrm{V}$ to 0.447 in the oxido complex, -0.222 in the sulfido, and -0.331 in the seleno complex.

The strength of the interaction between ligand orbitals and the central vanadium orbitals was investigated by second-order interaction energy (E2) [23]. This analysis examines all possible interactions between occupied (donor) Lewis-type NBOs and empty Rydberg (non-Lewis-type) NBOs of the vanadium atom. The higher the interaction energy is, the more the electrons are delocalized onto the central atom thereby increasing the stability of the complex [28]. For the oxido complex, the notable $E^{2}$ values are $19.10,4.35$, and $3.60 \mathrm{kcal} / \mathrm{mol}$ for $\mathrm{LP}(1) \mathrm{O} 5 \rightarrow \mathrm{RY}^{*}(1) \mathrm{V}$, $\mathrm{LP}(1) \mathrm{O} 5 \rightarrow \mathrm{RY}^{*}(8) \mathrm{V}$, and $\mathrm{LP}(1) \mathrm{O} 5 \rightarrow \mathrm{RY}^{*}(9) \mathrm{V}$ which shows a high delocalization of nonbonding(n) electrons from the $\mathrm{O} 5$ atom into non-Lewis-type vanadium orbitals with the strongest interaction being between LP(1)O5 and $\mathrm{RY}^{*}(1) \mathrm{V}$. Similarly, the nonbonding electrons on the methoxido oxygen were delocalized into Rydberg orbitals of the vanadium ion with the following interaction energies: 7.46 and $1.09 \mathrm{kcal} / \mathrm{mol}$ for $\mathrm{LP}(1) \mathrm{O} 6 \rightarrow \mathrm{RY}^{*}(2) \mathrm{V}$ and $\mathrm{LP}(1) \mathrm{O} 6 \rightarrow \mathrm{RY}^{*}(5) \mathrm{V}$, respectively. Other interactions were also observed involving nonbonding electrons on the chlorido ligands as follows: $\mathrm{LP}(2) \mathrm{Cl} 3 \rightarrow \mathrm{RY}^{*}(3) \mathrm{V}$, $\mathrm{LP}(3) \mathrm{Cl} \rightarrow \mathrm{RY}^{*}(4) \mathrm{V}, \mathrm{LP}(2) \mathrm{Cl} 4 \rightarrow \mathrm{RY}^{*}(3) \mathrm{V}$, and $\mathrm{LP}(3) \mathrm{Cl} 4 \rightarrow$ $\mathrm{RY}^{*}(4) \mathrm{V}$ with energies $3.41,2.85,3.83$, and $2.77 \mathrm{kcal} / \mathrm{mol}$, respectively. Although these interactions have significant binding energies, they are not as strong as those involving the oxido and methoxido ligands. In the case of the sulfido complex, the highest interaction energy of $9.26 \mathrm{kcal} / \mathrm{mol}$ was observed for $\mathrm{LP}(1) \mathrm{S} 21 \rightarrow \mathrm{RY} \mathrm{Y}^{*}(1) \mathrm{V}$. Although this shows 
TABLE 4: The 3d-orbital occupancy and energy of the central vanadium ion in the various complexes.

\begin{tabular}{|c|c|c|c|c|c|c|}
\hline \multirow{2}{*}{ Orbital } & \multicolumn{2}{|c|}{ A } & \multicolumn{2}{|c|}{ B } & \multicolumn{2}{|c|}{$\mathrm{C}$} \\
\hline & Occupancy & Energy & Occupancy & Energy & Occupancy & Energy \\
\hline$d_{x y}$ & 0.6890 & -0.204 & 0.8219 & -0.210 & 0.8744 & -0.193 \\
\hline$d_{x z}$ & 0.7166 & -0.203 & 0.7369 & -0.210 & 0.9648 & -0.205 \\
\hline$d_{y z}$ & 0.8034 & -0.230 & 0.9646 & -0.238 & 0.6912 & -0.198 \\
\hline$d_{x^{2}-y^{2}}$ & 0.7676 & -0.229 & 0.8871 & -0.226 & 0.8740 & -0.240 \\
\hline$d_{z^{2}}$ & 0.7618 & -0.208 & 0.8151 & -0.218 & 0.8464 & -0.235 \\
\hline
\end{tabular}

A: $\mathrm{VOCl}_{2}(\mathrm{OMe})(\mathrm{HOMe})_{2}, \mathrm{~B}: \mathrm{VSCl}_{2}(\mathrm{OMe})(\mathrm{HOMe})_{2}$, and C: $\mathrm{VSeCl}_{2}(\mathrm{OMe})(\mathrm{HOMe})_{2}$.

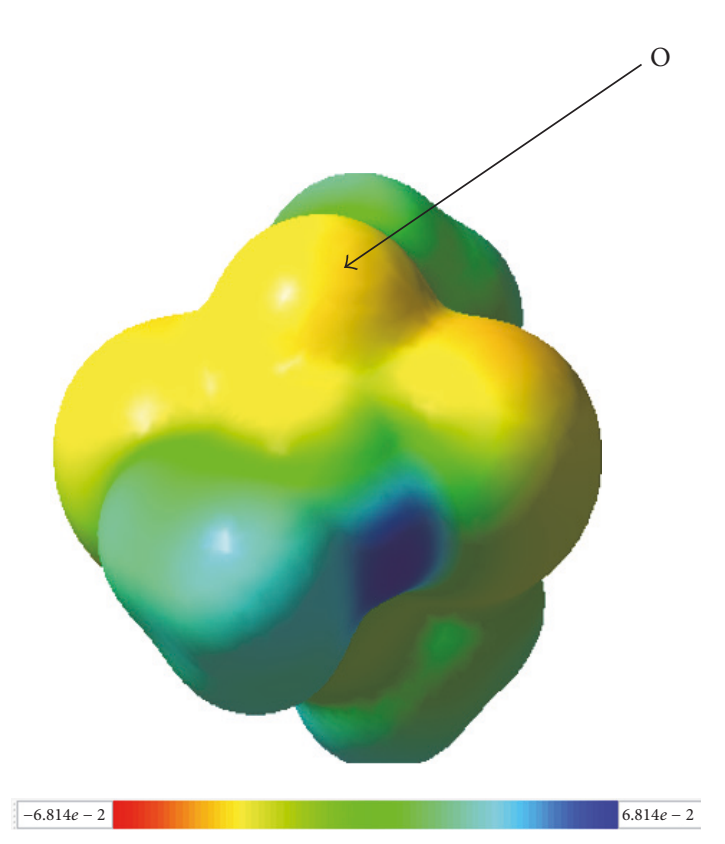

(A)

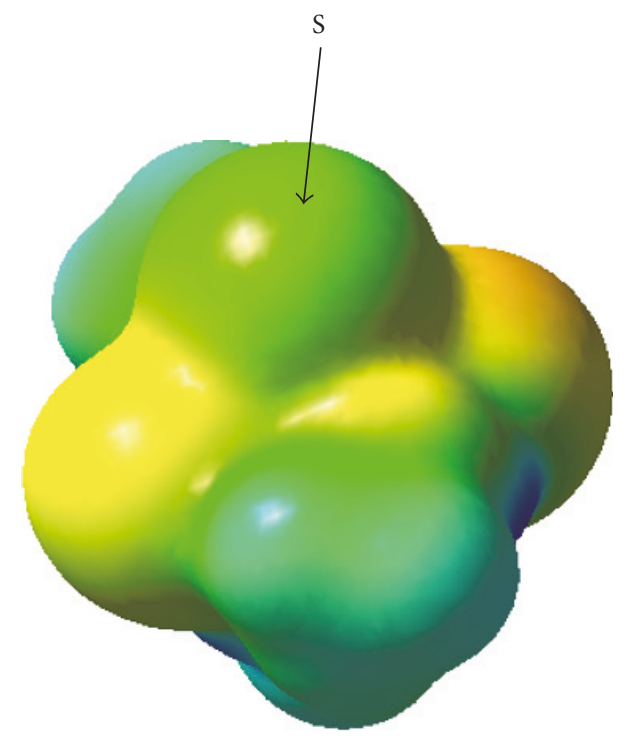

$-6.814 e-2$

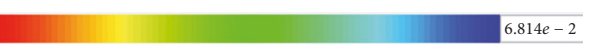

(B)

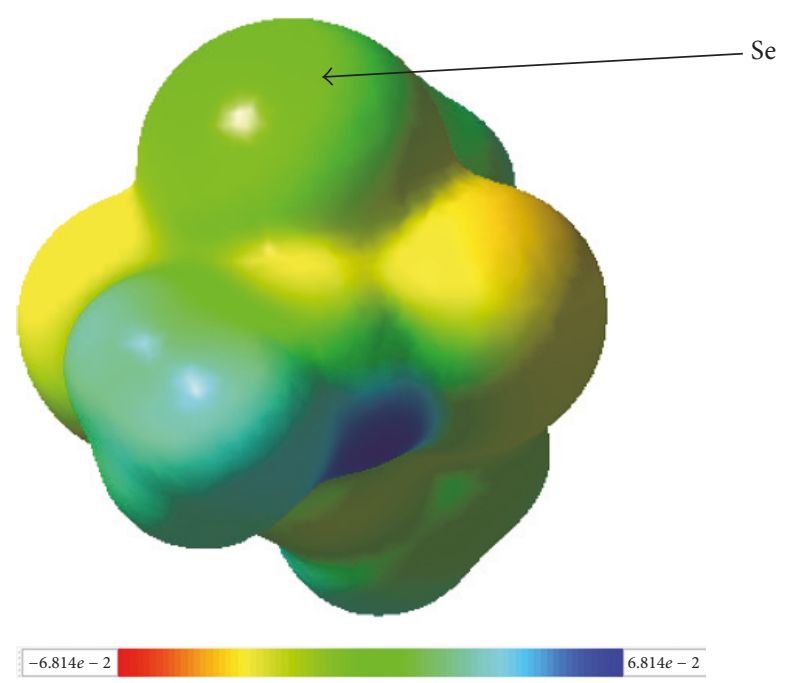

(C)

FIgURE 2: The molecular electrostatic potential, in Hartrees, at the 0.001 electron $\mathrm{Bohr}^{-3}$ isodensity surface of the respective complexes. A: $\mathrm{VOCl}_{2}(\mathrm{OMe})(\mathrm{HOMe})_{2}, \mathrm{~B}: \mathrm{VSCl}_{2}(\mathrm{OMe})(\mathrm{HOMe})_{2}$, and $\mathrm{C}: \mathrm{VSeCl}_{2}(\mathrm{OMe})(\mathrm{HOMe})_{2}$. 


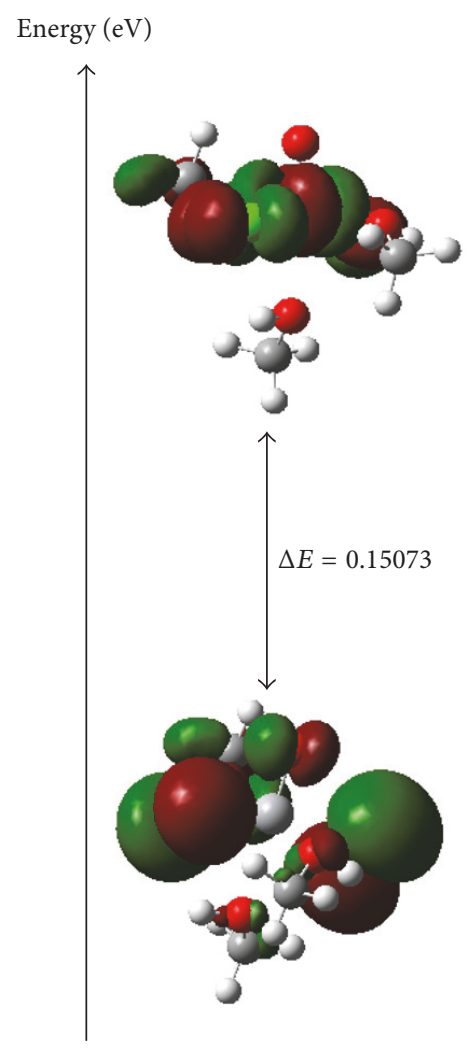

(A)

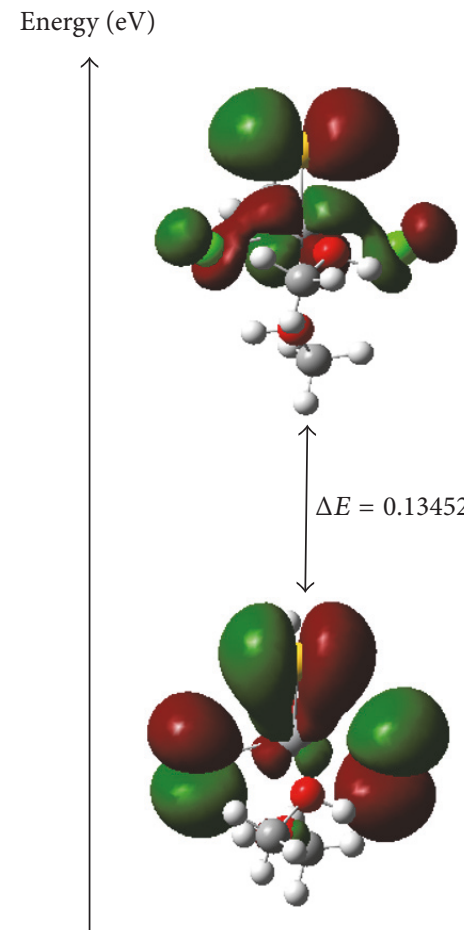

(B)

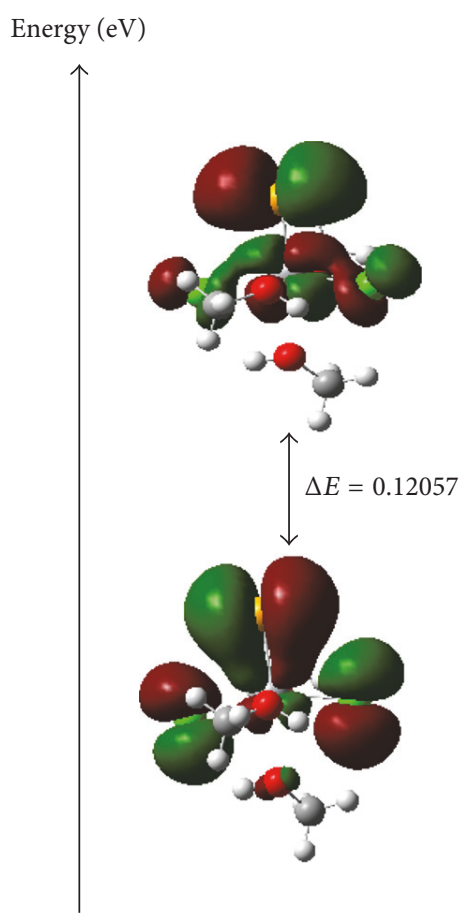

(C)

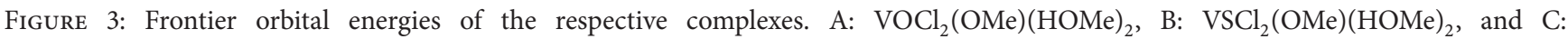
$\mathrm{VSeCl}_{2}(\mathrm{OMe})(\mathrm{HOMe})_{2}$.

significant delocalization of electrons, it was however less than twice the energy observed in the oxido complex. For the chlorido ligands, $2.61,2.91,3.31$, and $2.71 \mathrm{kcal} / \mathrm{mol}$ were recorded for $\mathrm{LP}(2) \mathrm{Cl} 3 \rightarrow \mathrm{RY}^{*}(3) \mathrm{V}, \quad \mathrm{LP}(3) \mathrm{Cl} 3 \rightarrow \mathrm{RY}^{*}(4) \mathrm{V}$, $\mathrm{LP}(2) \mathrm{Cl} 4 \rightarrow \mathrm{RY}^{*}(3) \mathrm{V}$, and $\mathrm{LP}(3) \mathrm{Cl} 4 \rightarrow \mathrm{RY}^{*}(4) \mathrm{V}$, respectively. These interaction energies were not much affected by the type of Ch ligand [23].

Despite the fact that selenium has the largest electron cloud among the selected chalcogens $(\mathrm{O}, \mathrm{S}, \mathrm{Se})$, least interaction energies were recorded for molecular orbitals of the seleno complex. A value of $4.83 \mathrm{kcal} / \mathrm{mol}$ (the highest) was observed for $\mathrm{LP}(1) \mathrm{Se} 21 \rightarrow \mathrm{RY}^{*}(2) \mathrm{V}$ which was also less than twice the observed interaction energy for the $\mathrm{LP}(1) \mathrm{S} 21 \rightarrow \mathrm{RY}{ }^{*}$ (1)V delocalization. Generally, the interaction energies decrease in the order, $\mathrm{O}>\mathrm{S}>\mathrm{Se}$. There were also significant ligand-to-metal charge transfer interactions [27] which contributed to the lowering of the formal charges on the vanadium ion from $+\mathrm{V}$ to those observed in Table 3 . The above inference confirms the relative stability of oxidovana$\operatorname{dium}(\mathrm{V})$ complexes [8] as compared to the sulfido and seleno congeners.

The frontier orbitals direct the electronic and chemical properties of molecules [29]. As shown qualitatively in Figure 3, the highest occupied molecular orbitals (HOMOs) have higher electron probabilities on the ligands with the lowest unoccupied molecular orbitals (LUMOs) being predominantly metal based. These observations support the ligand-to-metal charge transfer interactions discussed above. The HOMO-LUMO gap also decreases in the order oxido > sulfide $>$ seleno making the oxido complex the most stable.

Finally, the full interaction map for the reference complex [17] showing regions of hydrogen bond donor and acceptor propensities and also possibilities for halogen bonding is given in Figure 4. The study shows that the hydrogen bond acceptor peaks on the methanol $(\mathrm{O}-\mathrm{H})$ are higher than those on the methyl groups. There are however no interaction maps along the $\mathrm{V}=\mathrm{O}$ and $\mathrm{V}-\mathrm{Cl}$ bond axes. This confirms earlier findings by Cui et al. [17] that the methanol $(\mathrm{O}-\mathrm{H})$ ligands interact with the chlorido ligands of symmetrically related molecules through $\mathrm{O}-\mathrm{H} \cdots \mathrm{Cl}$ hydrogen bonds to generate a unique two-dimensional framework. The weak hydrogen bond interaction with the chlorido ligand is as a result of its relatively high electron density but this is not high enough to afford any halogen bonding [20] interaction in the crystal structure.

Generally, this work has been shown by DFT computational analyses that octahedral solvated (methanol) oxovana$\operatorname{dium}(\mathrm{V})$ complexes bearing chlorido and methoxido ligands are more stable than the corresponding sulfido and seleno congeners because of substantial $\mathrm{O} p \pi-\mathrm{V} d \pi$ interactions and 


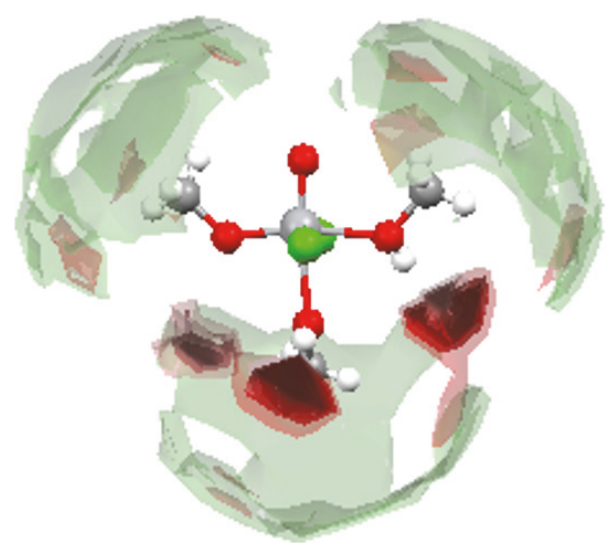

FIGURE 4: Full interaction map of the reference complex.

also nonbonding (lone pair) electron delocalization into nonLewis-type (Rydberg) orbitals on the vanadium atom.

\section{Conclusion}

In this paper, the relative stability of three octahedral solvent (methanol) coordinated chalcogenido (O, S, Se) vanadium $(\mathrm{V})$ complexes bearing chlorido ligands has been investigated by DFT computational analyses. The stability of the complexes is in the order $\mathrm{O}>\mathrm{S}>\mathrm{Se}$. This is in agreement with the relatively large number of oxovanadium complexes reported in the literature. According to the study, there is greater $\mathrm{O} \mathrm{p} \pi-\mathrm{V} \mathrm{d} \pi$ interaction resulting in a larger HOMO-LUMO gap relative to the other congeners. Second-order perturbation analyses also revealed substantial delocalization of oxido lone pair electrons into vacant nonLewis-type (Rydberg) orbitals as compared to the sulfido and seleno analogues. Full interaction map of the reference complex confirms hydrogen bonding interactions involving the methanol $(\mathrm{O}-\mathrm{H})$ and the chlorido ligand. There are however no interaction peaks on the oxido and chlorido ligands to promote halogen bonding in the crystal structure.

\section{Conflicts of Interest}

The authors declare that there are no conflicts of interest regarding the preparation and publication of this manuscript.

\section{Acknowledgments}

The authors are grateful to The Cambridge Crystallographic Data Centre (CCDC) for the opportunity to use the Cambridge Structural Database (CSD) for the molecular searches and full interaction map (FIM) studies.

\section{References}

[1] T. M. Trnka and G. Parkin, "A survey of terminal chalcogenido complexes of the transition metals: trends in their distribution and the variation of their $\mathrm{M}=\mathrm{E}$ bond lengths," Polyhedron, vol. 16, no. 7, pp. 1031-1045, 1997.
[2] A. V. Firth, E. Witt, and D. W. Stephan, "Thermal reactions of titanium thiolates: Terminal titanium sulfides in C-S bond cleavage reactions," Organometallics, vol. 17, no. 17, pp. 37163722, 1998.

[3] K. Kim, C. Jo, S. Easwaramoorthi, J. Sung, D. H. Kim, and D. G. Churchill, "Crystallographic, photophysical, NMR spectroscopic and reactivity manifestations of the " 8 -heteroaryl effect" in 4,4-Difluoro-8- $\left(\mathrm{C}_{4} \mathrm{H}_{3} X\right)$-4-bora-3a,4a-diaza-s-indacene $(X$ = O, S, Se) (BODIPY) systems," Inorganic Chemistry, vol. 49, no. 11, pp. 4881-4894, 2010.

[4] J. Pisk, J.-C. Daran, R. Poli, and D. Agustin, "Pyridoxal based ONS and ONO vanadium(V) complexes: structural analysis and catalytic application in organic solvent free epoxidation," Journal of Molecular Catalysis A: Chemical, vol. 403, pp. 52-63, 2015.

[5] C. Djordjevic and G. L. Wampler, "Antitumor activity and toxicity of peroxo heteroligand vanadates $(\mathrm{V})$ in relation to biochemistry of vanadium," Journal of Inorganic Biochemistry, vol. 25, no. 1, pp. 51-55, 1985.

[6] P. Noblía, M. Vieites, B. S. Parajón-Costa et al., "Vanadium(V) complexes with salicylaldehyde semicarbazone derivatives bearing in vitro anti-tumor activity toward kidney tumor cells (TK-10): crystal structure of $\left[\mathrm{V}^{V} \mathrm{O}_{2}\right.$ (5-bromosalicylaldehyde semicarbazone)]," Journal of Inorganic Biochemistry, vol. 99, no. 2, pp. 443-451, 2005.

[7] A. G. J. Ligtenbarg, R. Hage, and B. L. Feringa, "Catalytic oxidations by vanadium complexes," Coordination Chemistry Reviews, vol. 237, no. 1-2, pp. 89-101, 2003.

[8] C. Simonnet-Jégat and F. Sécheresse, "Binary vanadium chalcogenide complexes," Chemical Reviews, vol. 101, no. 9, pp. 26012611, 2001.

[9] R. A. Shiels, K. Venkatasubbaiah, and C. W. Jones, "Polymer and silica supported tridentate schiff base vanadium catalysts for the asymmetric oxidation of ethyl mandelate-activity, stability and recyclability," Advanced Synthesis \& Catalysis, vol. 350, no. 17, pp. 2823-2834, 2008.

[10] M. R. Maurya, A. A. Khan, A. Azam et al., "Dinuclear oxidovanadium(IV) and dioxidovanadium(V) complexes of 5,5'-methylenebis(dibasic tridentate) ligands: synthesis, spectral characterisation, reactivity, and catalytic and antiamoebic activities," European Journal of Inorganic Chemistry, no. 35, pp. 5377-5390, 2009.

[11] E. Kwiatkowski, G. Romanowski, W. Nowicki, M. Kwiatkowski, and K. Suwińska, "Chiral dioxovanadium(V) complexes with single condensation products of 1,2-diaminocyclohexane and aromatic o-hydroxycarbonyl compounds: synthesis, characterization, catalytic properties and structure," Polyhedron, vol. 26, no. 12, pp. 2559-2568, 2007.

[12] K. Nomura and S. Zhang, "Design of vanadium complex catalysts for precise olefin polymerization," Chemical Reviews, vol. 111, no. 3, pp. 2342-2362, 2011.

[13] Y. Onishi, S. Katao, M. Fujiki, and K. Nomura, "Synthesis and structural analysis of (arylimido)vanadium(V) complexes containing phenoxyimine ligands: new, efficient catalyst precursors for ethylene polymerization," Organometallics, vol. 27, no. 11, pp. 2590-2596, 2008.

[14] W.-G. Jia, Y.-B. Huang, Y.-J. Lin, and G.-X. Jin, "Syntheses and structures of half-sandwich iridium(III) and rhodium(III) complexes with organochalcogen $(\mathrm{S}, \mathrm{Se})$ ligands bearing $\mathrm{N}$ methylimidazole and their use as catalysts for norbornene polymerization," Dalton Transactions, no. 41, pp. 5612-5620, 2008. 
[15] A. Bauzá, D. Quiñonero, P. M. Deyà, and A. Frontera, "Halogen bonding versus chalcogen and pnicogen bonding: a combined Cambridge structural database and theoretical study," CrystEngComm, vol. 15, no. 16, pp. 3137-3144, 2013.

[16] K. S. C. Reid, P. F. Lindley, and J. M. Thornton, "Sulphuraromatic interactions in proteins," FEBS Letters, vol. 190, no. 2, pp. 209-213, 1985.

[17] H. Cui, M. Hummert, S. Dechert, and E. C. E. Rosenthal, "Structural diversity of chlorido methoxido- and ethoxidooxidovanadium(V) complexes: two-dimensional network, dimer, and unusual syn-oriented $\mathrm{V}=\mathrm{O}$ functionality," Inorganic Chemistry Communications, vol. 13, no. 6, pp. 769-773, 2010.

[18] D. Bibelayi, A. S. Lundemba, F. H. Allen et al., "Hydrogen bonding at $\mathrm{C}=\mathrm{Se}$ acceptors in selenoureas, selenoamides and selones," Acta Crystallographica Section B: Structural Science, Crystal Engineering and Materials, vol. 72, pp. 317-325, 2016.

[19] D. Papoutsakis, A. S. Ichimura, V. G. Young Jr., J. E. Jackson, and D. G. Nocera, "Structural and magnetic properties of vanadyl dichloride solvates: from molecular units to extended hydrogen-bonded solids," Dalton Transactions, no. 2, pp. 224228, 2004.

[20] P. A. Wood, T. S. G. Olsson, J. C. Cole et al., "Evaluation of molecular crystal structures using Full Interaction Maps," CrystEngComm, vol. 15, no. 1, pp. 65-72, 2013.

[21] R. D. Dennington, T. A. Keith, and J. M. Millam, GaussView 5.0.8. Gaussian Inc, 2008.

[22] M. J. Frisch, G. W. Trucks, H. B. Schlegel, G. E. Scuseria, M. A. Robb, and J. R. Cheeseman, Gaussian 09, Revision A. 1 [computer software], Wallingford, CT, USA: Gaussian, 2009.

[23] A. M. Mansour, "Coordination behavior of sulfamethazine drug towards $\mathrm{Ru}(\mathrm{III})$ and $\mathrm{Pt}(\mathrm{II})$ ions: synthesis, spectral, DFT, magnetic, electrochemical and biological activity studies," Inorganica Chimica Acta, vol. 394, pp. 436-445, 2013.

[24] C. Fliedel, V. Rosa, C. I. M. Santos et al., "Copper(II) complexes of bis(aryl-imino)acenaphthene ligands: synthesis, structure, DFT studies and evaluation in reverse ATRP of styrene," Dalton Transactions, vol. 43, no. 34, pp. 13041-13054, 2014.

[25] A. A. Markov, S. P. Dolin, N. I. Moiseeva, A. E. Gekhman, and I. I. Moiseev, "Aquaperoxovanadium(V) complexes: quantumchemical study," Russian Journal of Inorganic Chemistry, vol. 56, no. 5, pp. 738-744, 2011.

[26] D. C. Brower, J. L. Templeton, and D. M. P. Mingos, "Metal $\mathrm{d} \pi$-ligand $\pi$ conflicts in octahedral oxo, carbyne, and carbonyl complexes," Journal of the American Chemical Society, vol. 109, no. 17, pp. 5203-5208, 1987.

[27] S. Y. Ebrahimipour, M. Abaszadeh, J. Castro, and M. Seifi, "Synthesis, X-ray crystal structure, DFT calculation and catalytic activity of two new oxido-vanadium(V) complexes containing ONO tridentate Schiff bases," Polyhedron, vol. 79, pp. 138-150, 2014.

[28] J. Xu, L. Zhu, L. Wang et al., "The effect of anchoring group number on molecular structures and absorption spectra of triphenylamine sensitizers: A computational study," Journal of Molecular Modeling, vol. 18, no. 5, pp. 1767-1777, 2012.

[29] I. Avilov, P. Minoofar, J. Cornil, and L. De Cola, "Influence of substituents on the energy and nature of the lowest excited states of heteroleptic phosphorescent Ir(III) complexes: a joint theoretical and experimental study," Journal of the American Chemical Society, vol. 129, no. 26, pp. 8247-8258, 2007. 

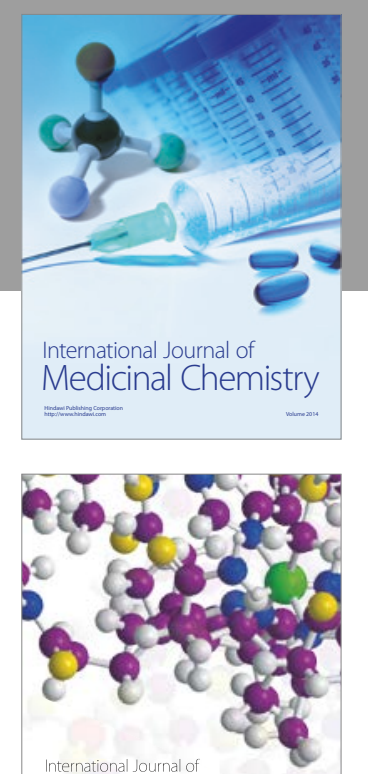

Carbohydrate Chemistry

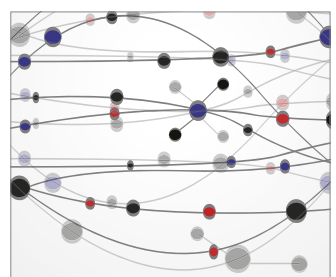

The Scientific World Journal
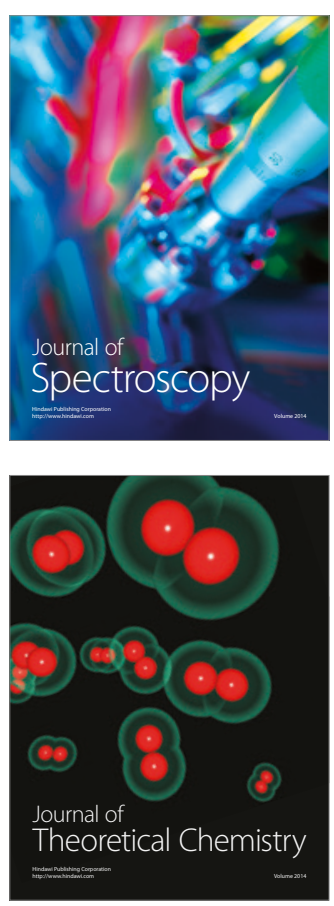
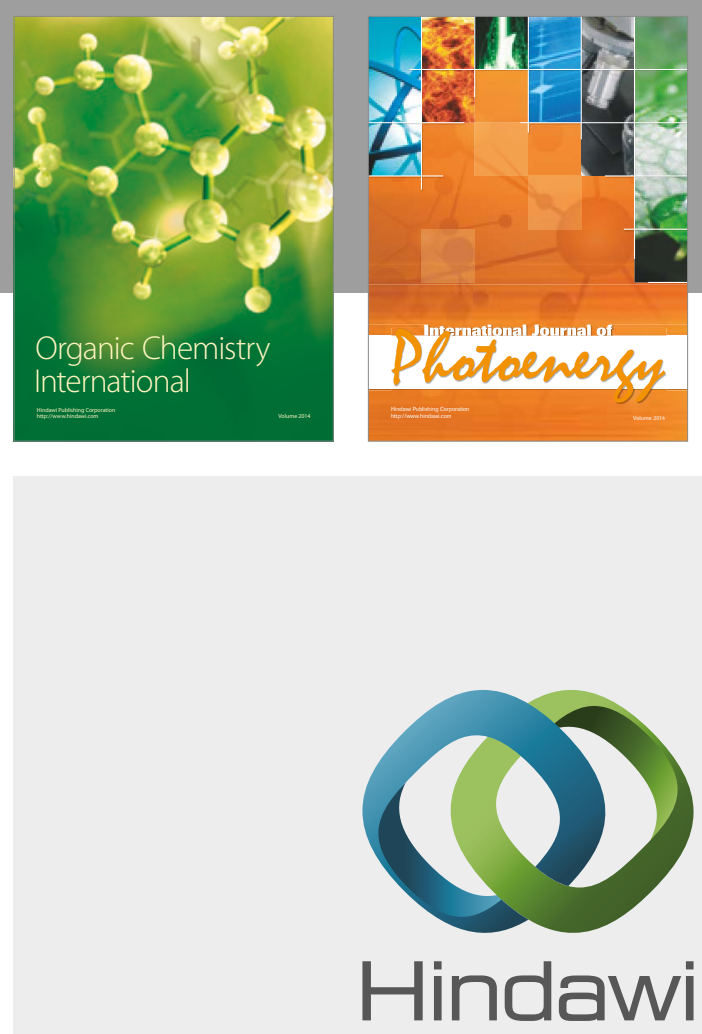

Submit your manuscripts at

https://www.hindawi.com

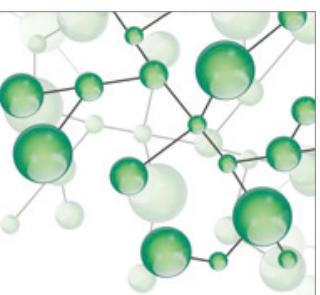

International Journal of

Inorganic Chemistry

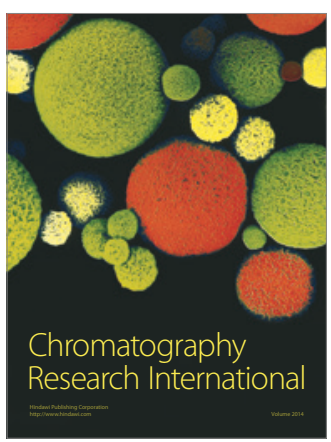

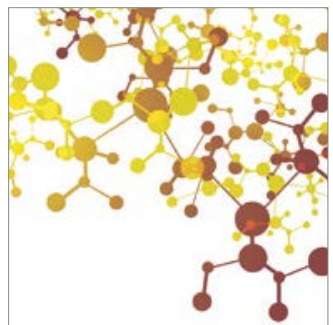

Applied Chemistry
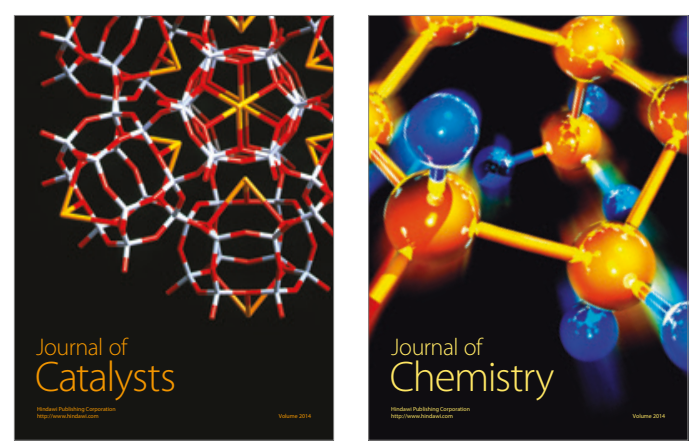
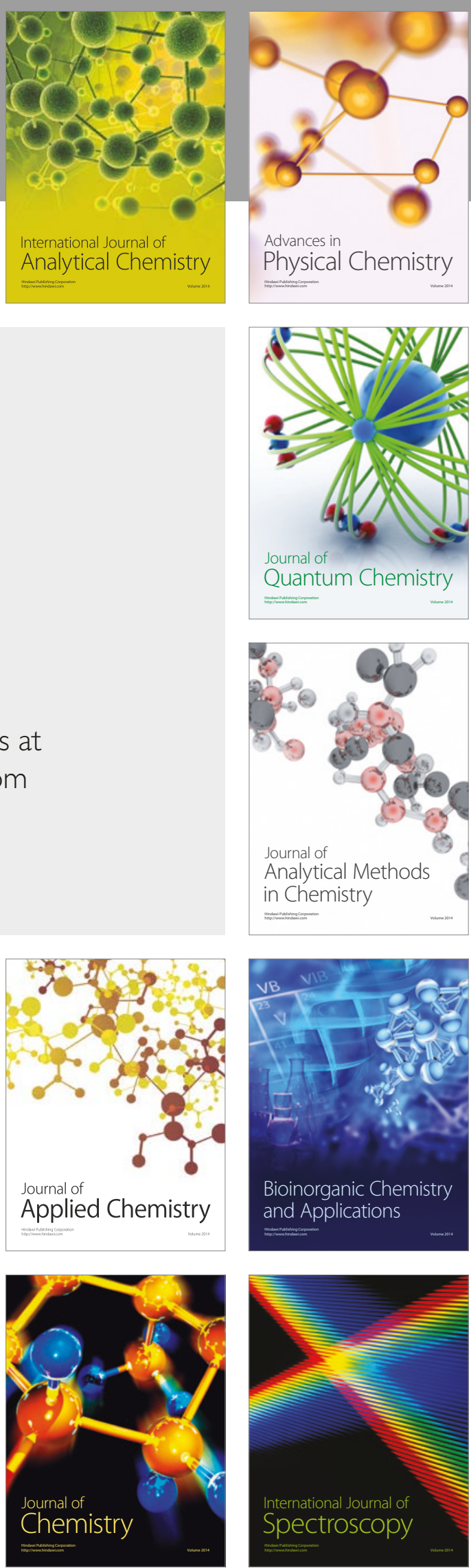